\title{
Decerebrate Posture with Roving Eye Movement
}

\author{
Yoko Warabi ${ }^{1,2}$ and Yoji Onishi ${ }^{1,3}$
}

Key words: decerebrate rigidity, roving eye movement, cerebral hemisphere, brainstem, midbrain

(Intern Med 50: 529-530, 2011)

(DOI: 10.2169/internalmedicine.50.4774)

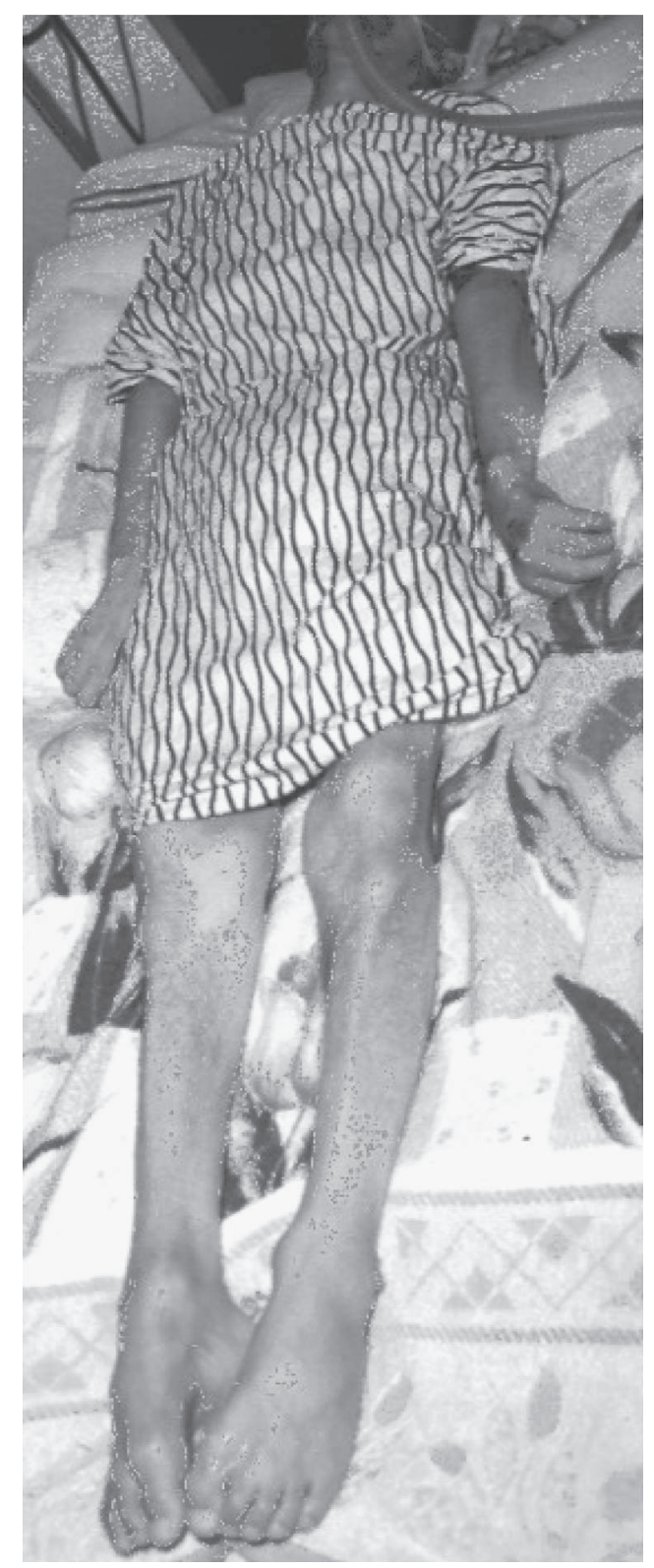

Picture 1.
A 70-year-old man with atrial fibrillation presented with generalized convulsion. The following morning, he presented with decerebrate posture and roving eye movement (Picture 1). Magnetic resonance imaging (MRI) demonstrated intact brainstem (Picture 2a) and cerebral embolism with occlusion of the right middle cerebral artery and left carotid artery (Picture 2b).

Decerebrate posture in humans is generally recognized as a sign of midbrain damage. Conversely, roving eye movement is a sign of brainstem preservation, that is, a sign of intact eye movement control system at the brainstem. Coexistence of these two signs seems to be paradoxical.

In the posture control system, dysfunction of reticular inhibitory area is important for decerebrate posture. Although transection of reticular formation at the critical point between the superior colliculus and inferior colliculus is recognized as the major cause of decerebrate posture, bilateral and massive damage of the descending connection from the cerebral cortex through corticoreticular fibers can also cause decerebrate posture. In fact, a condition termed "decerebrate rigidity" by Sherrington based on an original monkey experiment was the result of ligation of the carotid arteries and removal of the cerebral hemispheres (1). Thus, decerebrate posture with roving eye movement represents bilateral damage of cerebral hemispheres with an intact brainstem. The seemingly paradoxical combination of decerebrate posture and roving eye movement may appear in some patients whose posture control system (bilateral reticulospinal tracts or others) is involved and eye movement control structures at the brainstem are intact.

The authors state that they have no Conflict of Interest (COI).

The patient gave informed consent.

\footnotetext{
${ }^{1}$ Department of Neurology, Niigata City General Hospital, Japan, ${ }^{2}$ Department of Neurology, Tokyo Metropolitan Neurological Hospital, Japan and ${ }^{3}$ Onishi Clinic, Neurology and Internal Medicine, Japan

Received for publication November 1, 2010; Accepted for publication November 14, 2010

Correspondence to Dr. Yoko Warabi, ywarabi@tmnh.fuchu.tokyo.jp
} 


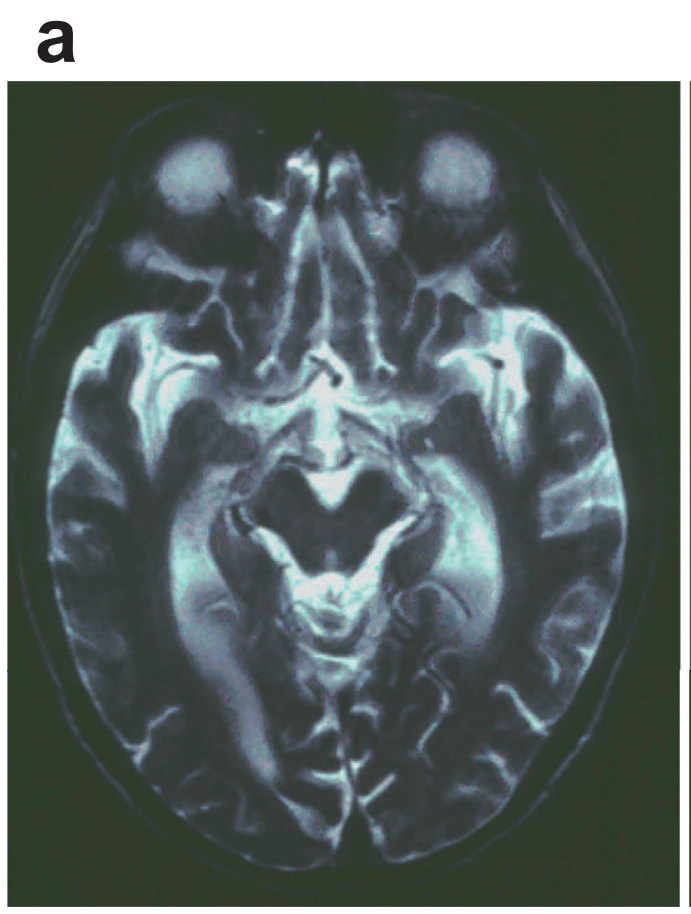

\section{b}

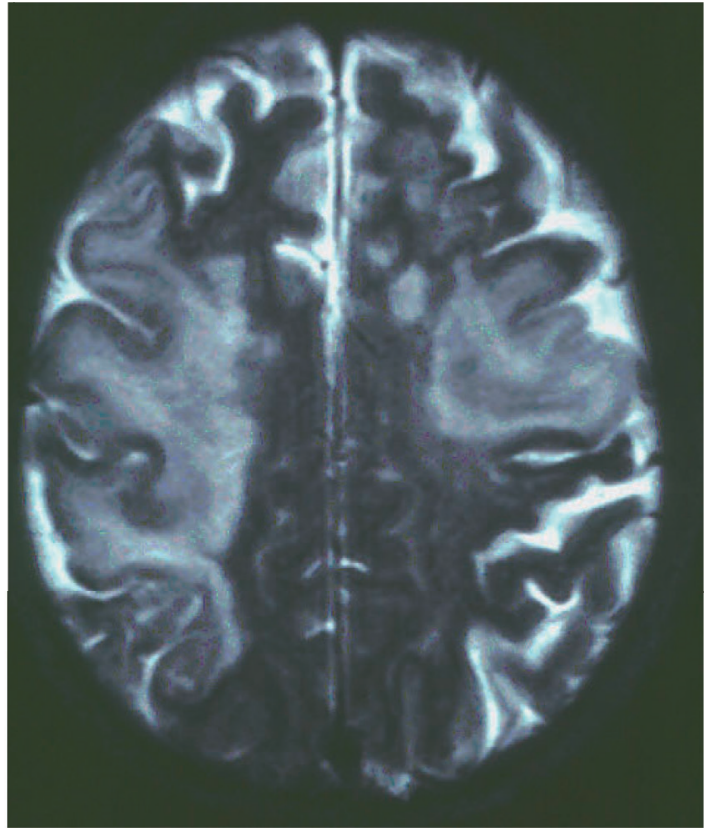

Picture 2.

\section{Reference}

1. Sherrington CS. Decerebrate rigidity, and reflex coordination of movements. J Physiol 22: 319-332, 1898.

(C) 2011 The Japanese Society of Internal Medicine http://www.naika.or.jp/imindex.html 